\title{
Diversity and spatial distribution of sediment ammonia-oxidizing crenarchaeota in response to estuarine and environmental gradients in the Changjiang Estuary and East China Sea

\begin{abstract}
Correspondence
Hongyue Dang

DangHY20042000

@yahoo.com.cn
\end{abstract} \\ Tiegang Li \\ tgli@ms.qdio.ac.cn \\ Received 24 September 2007 \\ Revised 8 February 2008 \\ Accepted 12 February 2008

\author{
Hongyue Dang, ${ }^{1,2}$ Xiaoxia Zhang, ${ }^{1,2,3}$ Jin Sun, ${ }^{1,2,3}$ Tiegang Li, ${ }^{2}$ \\ Zhinan Zhang ${ }^{3}$ and Guanpin Yang ${ }^{3}$ \\ ${ }^{1}$ Centre for Bioengineering and Biotechnology, China University of Petroleum (East China), \\ Qingdao 266555, China \\ ${ }^{2}$ Key Laboratory of Marine Geology and Environment, Institute of Oceanology, Chinese Academy of \\ Sciences, Qingdao 266071, China \\ ${ }^{3}$ Life Sciences and Technology College, Ocean University of China, Oingdao 266003, China
}

\begin{abstract}
Ammonia-oxidizing archaea (AOA) have recently been found to be potentially important in nitrogen cycling in a variety of environments, such as terrestrial soils, wastewater treatment reactors, marine waters and sediments, and especially in estuaries, where high input of anthropogenic nitrogen is often experienced. The sedimentary AOA diversity, community structure and spatial distribution in the Changjiang Estuary and the adjacent East China Sea were studied. Multivariate statistical analysis indicated that the archaeal amoA genotype communities could be clustered according to sampling transects, and the station located in an estuarine mixing zone harboured a distinct AOA community. The distribution of AOA communities correlated significantly with the gradients of surface-water salinity and sediment sorting coefficient. The spatial distribution of putative soil-related AOA in certain sampling stations indicated a strong impact of the Changjiang freshwater discharge on the marine benthic microbial ecosystem. Besides freshwater, nutrients, organic matter and suspended particles, the Changjiang Diluted Water might also contribute to the transport of terrestrial archaea into the seawater and sediments along its flow path.
\end{abstract}

\section{INTRODUCTION}

Microbial nitrification, the process of ammonia oxidation to nitrate via nitrite $\left(\mathrm{NH}_{3} \rightarrow \mathrm{NO}_{2}^{-} \rightarrow \mathrm{NO}_{3}^{-}\right)$, is a key component of the global nitrogen $(\mathrm{N})$ biogeochemical cycle. Over geological timescales, the $\mathrm{N}$ cycle is thought to have affected the global biogeochemical cycle of carbon and hence the content of atmospheric $\mathrm{CO}_{2}$ (Falkowski, 1997). On a local scale, microbial nitrification also contributes to the bioremediation of anthropogenic $\mathrm{N}$ eutrophication in estuarine and coastal environments (Francis et al., 2005; Caffrey et al., 2007), via coupled nitrification-denitrification

Abbreviations: AOA, ammonia-oxidizing archaea; CCA, canonical correspondence analysis; CDW, Changjiang Diluted Water; OrgN, organic nitrogen; OrgC, organic carbon; OTU, operational taxonomic unit; PCoA, principal coordinates analysis; TWC, Taiwan Warm Current.

The GenBank/EMBL/DDBJ accession numbers for the archaeal amoA gene sequences determined in this study are EU025140 to EU025186.

Four supplementary figures are available with the online version of this paper. or nitrification-anammox (anaerobic oxidation of ammonium) processes (Seitzinger, 1988; Coolen et al., 2007; Lam et al., 2007).

The recent discovery that some mesophilic archaea in the kingdom Crenarchaeota possess the potential for chemoautotrophic ammonia oxidation, the first and rate-limiting step in microbial nitrification, suggests an important role of archaea in the $\mathrm{N}$ cycle (Venter et al., 2004; Konneke et al., 2005; Treusch et al., 2005). Crenarchaeota are ubiquitous and abundant in marine waters and sediments (DeLong, 1992; Vetriani et al., 1999). Genomic and environmental microbiological studies indicated that the crenarchaeota microbiota could be chemoautotrophic (Wuchter et al., 2003; Herndl et al., 2005; Hallam et al., 2006a, b; Ingalls et al., 2006), heterotrophic (Ouverney \& Fuhrman, 2000; Teira et al., 2006) or mixotrophic. The crenarchaeotal ammonia mono-oxygenase gene (amoA) was found to be pervasive in the ocean (Francis et al., 2005; Beman \& Francis, 2006; Beman et al., 2007; Lam et al., 2007; Nakagawa et al., 2007). Quantitative studies also 
indicated that ammonia-oxidizing archaea (AOA) appear to be more abundant than ammonia-oxidizing bacteria (Wuchter et al., 2006; Mincer et al., 2007; Nakagawa et al., 2007), and the potential estuarine nitrification rates increased as abundance of AOA amoA increased (Caffrey et al., 2007), further suggesting the ecological importance of the AOA.

Although nitrification is of particular importance in estuarine and coastal sediments, and the ability to oxidize ammonia may be broadly distributed in the crenarchaeota (Nicol \& Schleper, 2006; Caffrey et al., 2007; Cavicchioli et al., 2007; Francis et al., 2007), only a few studies have actually examined the diversity and spatial distribution of the sedimentary AOA communities (Francis et al., 2005; Beman \& Francis, 2006). These studies have shown that diverse AOA phylotypes and distinct AOA communities exist in different marine environments both on a large geographical scale and in local estuarine gradients, demonstrating that their spatial distribution may be associated with environmental conditions (Francis et al., 2005; Beman \& Francis, 2006). However, these studies were limited to the temperate and subtropical coast of the East Pacific Ocean. The sedimentary diversity and spatial distribution of AOA are largely unknown in other coastal areas of the world oceans, including most large river estuaries.

The Changjiang River (historically called the Yangtze River) is the third-largest river in the world, with a huge water discharge of $9.24 \times 10^{11} \mathrm{~m}^{3}$ per year, equivalent to $1 / 50$ of the water volume of the adjacent East China Sea (Yanagi, 1994), the largest continental marginal sea in the western Pacific. This river also delivers more than $7.5 \times 10^{10}$ moles per year of $\mathrm{N}$ nutrients to the East China Sea (Zhu et al., 2005). Thus, the estuary and shelf region has been the research focus of a series of international programmes, such as JGOFS (Joint Global Ocean Flux Study), GLOBEC (Global Ocean Ecosystems Dynamics), LOICZ (Land-Ocean Interactions in the Coastal Zone) and IMBER (Integrated Marine Biogeochemistry and Ecosystem Research), due to its importance in fishery, climate change and environmental issues, such as pollution, eutrophication, red tides and hypoxia (Li et al., 2002; Li \& Daler, 2004; Chai et al., 2006). Being the interface of land, freshwater and marine environments, this region is extremely complicated and dynamic, due to the variability of freshwater input, currents and anthropogenic inputs, as well as the construction and operation of the Three Gorges Dam in the middle reaches of the Changjiang River (Zhang et al., 1999; Jiao et al., 2007). Micro-organisms may play important roles in this unique large river estuarine ecosystem, particularly in biogeochemical cycles and food webs. However, studies of microbial ecology started here only recently (Sekiguchi et al. 2002; Zhang \& Jiao, 2007). It has been shown that marine crenarchaeota dominate the pelagic archaeal community, and 16S rRNA gene sequences related to autotrophic ammonia-oxidizing 'Candidatus
Nitrosopumilus maritimus' were detected in the estuarine area (Zeng et al., 2007). Due to environmental heterogeneity and intense riverine input of anthropogenic $\mathrm{N}$, we hypothesized that the Changjiang Estuary and the adjacent East China Sea could harbour diverse sedimentary AOA, with distinct community structures and diversity in response to specific estuarine, geochemical and eutrophication gradients. To test this hypothesis, a molecular study based on the archaeal amoA functional marker gene was conducted.

\section{METHODS}

Study area and sampling sites. Sediment samples were collected from the Changjiang Estuary and adjacent East China Sea during a cruise of the R/V 'Dong Fang Hong 2', 14-20 June, 2006. Two sampling transects and a total of seven sampling stations were chosen for the current AOA project (Fig. 1). Sediments were collected with a stainless steel $0.1 \mathrm{~m}^{2}$ Gray O'Hara box corer and only undisturbed core samples with clear overlying water were used (Jonasson \& Olausson, 1966). Replicate surface sediment subcore samples down to $5 \mathrm{~cm}$ depth for microbiological and environmental analyses were taken with sterile $60 \mathrm{ml}$ syringes (luer end removed), homogenized and stored in airtight sterile plastic bags at $-20{ }^{\circ} \mathrm{C}$ during the cruise and $-80{ }^{\circ} \mathrm{C}$ after returning to the laboratory.

Environmental physico-chemical analyses. At each station, in situ measurements of the physico-chemical parameters of seawater (conductivity, density, depth, dissolved oxygen, $\mathrm{pH}$, turbidity, salinity and temperature) were recorded at various water depths with a SeaBird model SBE9 conductivity-temperature-depth recorder (SeaBird Electronics) (Table 1). Other parameters were measured in the laboratory. A nutrient AutoAnalyser (QUAATRO; Bran + Luebbe) was used to measure pore-water dissolved $\mathrm{N}$ and $\mathrm{P}$ concentrations: nitrate $\left(\mathrm{NO}_{3}-\mathrm{N}\right)$, nitrite $\left(\mathrm{NO}_{2}-\mathrm{N}\right)$, ammonium $\left(\mathrm{NH}_{4}-\mathrm{N}\right)$ and phosphate $\left(\mathrm{PO}_{4}-\mathrm{P}\right)$. Sediment total organic carbon $(\mathrm{OrgC})$ and nitrogen $(\mathrm{OrgN})$ contents were measured with a PE2400 series II CHNS/O elemental analyser (Perkin Elmer). A Cilas 940L laser granulometer (Company Industrielle des Lasers) was used for sediment grain size analysis and median grain size, sorting coefficient, skewness and kurtosis were calculated (Table 1).

DNA extraction and archaeal amoA gene clone library analyses. DNA was extracted from $0.3 \mathrm{~g}$ sediment using a FastPrep DNA Extraction Kit for Soil and a FastPrep FP120 Cell Disrupter instrument (Qbiogene) (Francis et al., 2005; Beman \& Francis, 2006). Replicate DNA extractions from three subcore samples were pooled for each sampling station. Archaeal amoA fragments ( 635 bp) were amplified in a PTC-200 thermal cycler (Bio-Rad) with published primers Arch-amoAF and Arch-amoAR and the corresponding PCR protocol (Francis et al., 2005; Beman \& Francis, 2006). PCR products from five reactions were pooled to minimize PCR bias, gel-purified, and ligated into pMD19-T simple vectors (Takara) according to the manufacturer's instructions. The hybrid vectors were used to transform Escherichia coli TOP10 competent cells prepared by using the calcium chloride protocol (Sambrook \& Russell, 2001). Recombinants were selected by using X-Gal-IPTG Luria-Bertani (LB) indicator plates supplemented with $100 \mu \mathrm{g}$ ampicillin $\mathrm{ml}^{-1}$. Each clone library was constructed by random selection of approximately 100 white colonies from a single plate. A plasmid miniprep method was used for recombinant plasmid preparations (Dang \& Lovell, 2000). Cloned amoA fragments were reamplified using primers M13-D (5'-AGGGTTTTCCCAGTCACGACG-3') and RV-M (5'-GAGCGGATAACAATTTCACACA- 


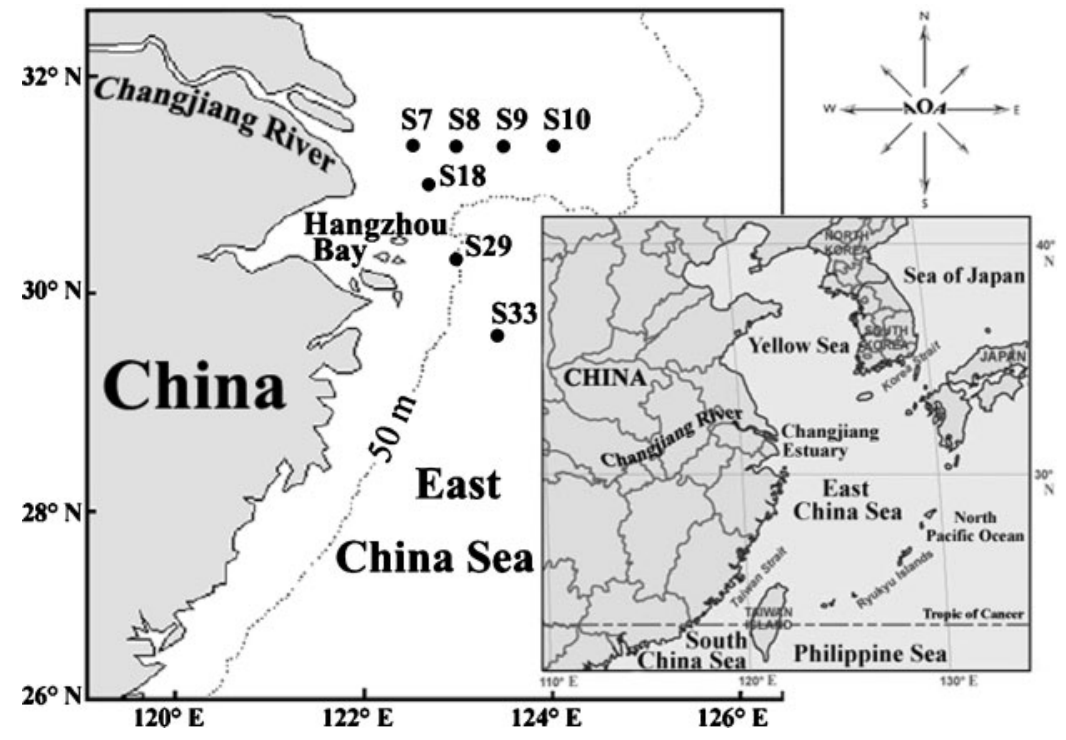

Fig. 1. Maps showing the sampling transects and stations in the Changjiang Estuary and the adjacent East China Sea.
GG-3'), flanking the insertion site of the vector. PCR products were screened for correct size and purity by $1 \%$ agarose gel electrophoresis.

Amplimers with the correct size were digested using MspI and HhaI (Fermentas). Restriction fragments were resolved by electrophoresis on $4 \%$ agarose gels in $0.5 \times$ TBE, and digitally photographed with an ImageMaster VDS imaging system (Pharmacia Biotech). The band patterns of the RFLP analysis were compared in order to identify redundant clones.

Clone vector primer RV-M was used for sequencing with an ABI 3770 automatic sequencer (Applied BioSystems). Several random clones from the same RFLP patterns resulted in identical amoA sequences; the genetic variation in each of the RFLP patterns was probably quite low. The resultant unique sequences were grouped into operational taxonomic units (OTUs) based on 95\% DNA sequence similarity calculated with the DOTUR program (Schloss \& Handelsman, 2005), to facilitate comparison with other studies (Francis et al., 2005; Beman \& Francis, 2006; Park et al., 2006; Beman et al., 2007). The sequences of the putative archaeal amoA genes were translated into conceptual amino acid sequences using the BioEdit program (Hall, 1999), and the online BLAST program (Altschul et al., 1997) from the GenBank database was used for retrieval of the closest matched sequences. AmoA sequences were aligned using the CLUSTAL_X program (Thompson et al., 1994) and phylogenetic trees constructed using the PROTDIST and NEIGHBOR programs of the PHYLIP package (version 3.66) (Felsenstein, 1989).

Statistical analyses. The estimated coverage of the constructed archaeal $a m o A$ gene libraries was calculated as $C=\left[1-\left(n_{1} / N\right)\right] \times 100$, where $n_{1}$ is the number of unique (frequency=1) amoA RFLP genotypes or OTUs detected in a library and $N$ is the total number of clones in the same library (Mullins et al., 1995). This value approximated the probability that all the unique sequences present in a given sample were represented at least once in the library.

Indices of the amoA genotype diversity (Shannon-Wiener $H$ and Simpson $D$ ) and evenness $(J)$ were calculated with amoA RFLP genotypes or OTUs of the clone libraries (Brown \& Bowman, 2001). Rarefaction analysis and two nonparametric richness estimators, the abundance-based coverage estimator $\left(S_{\mathrm{ACE}}\right)$ and the bias-corrected Chaol $\left(S_{\text {Chao } 1}\right.$ ), were calculated using the DOTUR program (Schloss \& Handelsman, 2005; Beman \& Francis, 2006). These diversity indices and richness estimators are useful statistical tools to compare the relative complexity of communities and to estimate the completeness of sampling.

The AOA community classification was determined with weighted UniFrac environmental clustering and principal coordinates analyses (PCoA) (Lozupone \& Knight, 2005; Lozupone et al., 2007). The online UniFrac program (http://bmf.colorado.edu/unifrac/index.psp) takes molecular evolutionary distances of the sequences and their environmental occurrences for microbial community similarity analyses, particularly suitable for sequence data. Correlations between AOA communities and environmental factors were analysed by canonical correspondence analysis (CCA) using the software Canoco (version 4.5, Microcomputer Power) (ter Braak \& Šmilauer, 2002). High occurrence of zero entries $(\sim 64 \%)$ in the species table (i.e. the OTU table) indicated that the unimodal CCA analysis was more suitable than the linear-model-based redundancy analysis (RDA) for our data (Lepš \& Šmilauer, 2003). The percentage frequency data of the amoA OTUs were used as the species input, and the environmental variables entered into the CCA were normalized (i.e. adjusted for a mean of 0 and SD of 1 via $Z$ transformation) (Magalhães et al., 2007). Manual deselection of collinear environmental variables and forward selection with significance tests of Monte Carlo permutations were used to build the optimal models of the microbe-environment relationship (Lepš \& Śmilauer, 2003). These multivariate statistical methods cope with major issues in microbial ecology, such as the distribution and relatedness of diversity and community structure with environmental variables or along an environmental gradient (Lozupone et al., 2007; Magalhães et al., 2007).

\section{RESULTS}

\section{Environmental hydrochemical and geochemical settings}

Changjiang River water entering the East China Sea in the flood (wet) season (usually from May to October) had low salinity, high temperature and high nutrient level, especially of $\mathrm{N}\left(\sim 7.5 \times 10^{10}\right.$ moles nitrate per year) (Zhu et al., 2005). Gradients of surface-water salinity, density and 
Table 1. In situ environmental parameters of the sampling stations in the Changjiang Estuary and the adjacent East China Sea

\begin{tabular}{|c|c|c|c|c|c|c|c|}
\hline \multirow[t]{2}{*}{ Environmental factor } & \multicolumn{7}{|c|}{ Station } \\
\hline & S7 & S8 & S9 & S10 & S18 & S29 & S33 \\
\hline Longitude $\left({ }^{\circ} \mathrm{E}\right)$ & 122.4813 & 122.9297 & 123.4797 & 123.9747 & 122.6178 & 122.8357 & 123.197 \\
\hline \multicolumn{8}{|l|}{ Surface water } \\
\hline Depth (m) & 3.0 & 3.0 & 3.0 & 3.0 & 3.0 & 3.0 & 3.0 \\
\hline Salinity $\left(\mathrm{PSU}^{\star}\right)$ & 20.4 & 27.4 & 31.7 & 32.1 & 21.5 & 29.1 & 28.0 \\
\hline Density $\left(\sigma_{\mathrm{t}}\right)$ & 13.34 & 18.75 & 22.11 & 22.38 & 14.07 & 19.67 & 18.51 \\
\hline Dissolved oxygen $(\mu \mathrm{M})$ & 235.34 & 279.90 & 252.97 & 257.42 & 246.24 & 342.80 & 305.90 \\
\hline $\mathrm{pH}$ & 8.22 & 8.46 & 8.44 & 8.39 & 8.27 & 8.63 & 8.55 \\
\hline Turbidity (FTU $\dagger$ ) & 12.03 & 0.97 & 0.66 & 0.37 & 3.95 & 1.78 & 0.38 \\
\hline Salinity (PSU) & 33.3 & 33.7 & 33.1 & 32.9 & 31.3 & 32.6 & 34.4 \\
\hline Density $\left(\sigma_{t}\right)$ & 23.80 & 23.94 & 23.53 & 23.37 & 22.01 & 22.86 & 24.83 \\
\hline Dissolved oxygen $(\mu \mathrm{M})$ & 149.53 & 173.53 & 186.23 & 218.87 & 171.55 & 192.92 & 183.52 \\
\hline $\mathrm{pH}$ & 8.27 & 8.27 & 8.34 & 8.32 & 8.24 & 8.39 & 8.31 \\
\hline Turbidity (FTU) & 37.33 & 12.29 & 4.33 & 2.41 & 122.13 & 16.72 & 2.33 \\
\hline \multicolumn{8}{|l|}{ Sediment pore-water } \\
\hline Salinity (PSU) & 30.0 & 32.0 & ND & 31.0 & 27.0 & 30.0 & $\mathrm{ND}$ \\
\hline $\mathrm{pH}$ & 7.31 & 7.45 & $\mathrm{ND}$ & 7.8 & 7.41 & 7.32 & ND \\
\hline $\mathrm{NH}_{4}-\mathrm{N}(\mu \mathrm{M})$ & 550.54 & 704.63 & ND & 153.90 & 503.02 & 1808.07 & $\mathrm{ND}$ \\
\hline $\mathrm{NO}_{2}-\mathrm{N}(\mu \mathrm{M})$ & 0.86 & 6.45 & ND & 6.98 & 9.39 & 3.07 & $\mathrm{ND}$ \\
\hline $\mathrm{NO}_{3}-\mathrm{N}(\mu \mathrm{M})$ & 4.06 & 1.97 & ND & 3.33 & 8.38 & 6.40 & ND \\
\hline Silt (\%) & 57.67 & 34.10 & 30.17 & 20.69 & 44.64 & 52.73 & 48.33 \\
\hline Clay (\%) & 13.32 & 11.83 & 10.51 & 6.57 & 15.75 & 23.61 & 27.46 \\
\hline Median grain size $(\varnothing)$ & 5.09 & 3.86 & 2.92 & 2.91 & 4.98 & 6.32 & 6.51 \\
\hline Sorting coefficient & 1.90 & 2.17 & 2.10 & 2.11 & 2.09 & 2.18 & 2.30 \\
\hline Skewness & 1.79 & 2.18 & 2.29 & 2.38 & 1.86 & 1.11 & 0.37 \\
\hline Kurtosis & 2.47 & 2.84 & 2.84 & 3.03 & 2.59 & 2.59 & 2.58 \\
\hline
\end{tabular}

ND, Not determined.

${ }^{\star} \mathrm{PSU}$, practical salinity units; $1 \mathrm{PSU} \approx 0.1 \%$.

$\dagger$ FTU, formazin turbidity units.

‡DIN, dissolved inorganic nitrogen.

conductivity along the two sampling transects indicated that strong freshwater runoff from the Changjiang River formed the characteristic Changjiang Diluted Water (CDW) in the East China Sea (Table 1). The northward intrusion of the Taiwan Warm Current (TWC) from the south along the $50 \mathrm{~m}$ isobath is another permanent feature of the East China Sea circulation in summer (Ichikawa \& Beardsley, 2002; Chen et al., 2003). The TWC saline water met with the CDW freshwater just off the Changjiang River mouth, forming salinity fronts around $122.5^{\circ} \mathrm{E}$. Most of the fine particles carried by the CDW were deposited in this estuarine mixing zone, and were responsible for the creation of the estuarine maximum turbidity zone (Table 1). Surface-water salinity and turbidity gradients showed that part of the CDW flowed in the south-eastward branch along the coastline during our sampling time, in good 
Table 2. Analyses of the archaeal amoA clone libraries constructed for the seven sedimentary sampling stations in the Changjiang Estuary and adjacent East China Sea

The calculations of the coverage, diversity indices and richness estimators are based on both RFLP genotypes (left of /) and OTUs (right of /).

\begin{tabular}{|c|c|c|c|c|c|c|c|c|c|}
\hline Station & $\begin{array}{l}\text { No. of } \\
\text { clones }\end{array}$ & $\begin{array}{c}\text { No. of RFLP } \\
\text { genotypes }\end{array}$ & $\begin{array}{l}\text { No. of } \\
\text { OTUs }\end{array}$ & $C(\%)$ & $H$ & $1 / D$ & $J$ & $S_{\mathrm{ACE}}$ & $S_{\text {Chao1 }}$ \\
\hline S7 & 87 & 24 & 16 & $86.2 / 96.6$ & $3.891 / 3.562$ & $11.839 / 10.421$ & $0.849 / 0.890$ & $41.7 / 17.5$ & $57.0 / 17.5$ \\
\hline S8 & 92 & 12 & 9 & $94.6 / 96.7$ & $2.374 / 2.204$ & $3.541 / 3.437$ & $0.662 / 0.695$ & $18.4 / 11.6$ & $17.0 / 12.0$ \\
\hline S9 & 90 & 9 & 6 & $95.6 / 98.9$ & $1.984 / 1.858$ & $2.998 / 2.967$ & $0.626 / 0.719$ & $14.0 / 6.4$ & $15.0 / 6.0$ \\
\hline S10 & 91 & 14 & 10 & $94.5 / 95.6$ & $3.068 / 2.649$ & $6.531 / 5.467$ & $0.806 / 0.797$ & $18.4 / 17.7$ & $24.0 / 16.0$ \\
\hline S18 & 90 & 16 & 12 & $90.0 / 95.6$ & $2.707 / 2.550$ & $4.495 / 4.339$ & $0.677 / 0.711$ & $35.6 / 15.1$ & $28.0 / 14.0$ \\
\hline S29 & 93 & 12 & 11 & $93.5 / 93.5$ & $2.140 / 1.936$ & $2.944 / 2.728$ & $0.597 / 0.560$ & 21.0/18.5 & $19.5 / 15.0$ \\
\hline S33 & 94 & 14 & 10 & $93.6 / 94.7$ & $3.021 / 2.453$ & $6.683 / 4.660$ & $0.793 / 0.738$ & $29.4 / 33.8$ & $21.5 / 20.0$ \\
\hline
\end{tabular}

accordance with previous findings in summer seasons (Chen et al., 2003; Zhu et al., 2005).

Due to the intrusion of the TWC, bottom water at the sampling stations usually had higher salinity than surface water (Table 1). The most significant gradients among the various bottom-water physico-chemical parameters were dissolved oxygen and turbidity. The S7 station was usually located inside the Changjiang Estuary seasonal oxygen minimum zone (Li et al., 2002). Although the bottom water did not reach anoxic conditions during our sampling period, the lowest dissolved oxygen value did occur at station S7 and obvious gradients existed along both the sampling transects as expected (Table 1). The bottomwater turbidity maxima at stations S18 and S7 indicated that, besides surface-water particulate matter sedimentation, seafloor surface sediment resuspension occurs intensely in this area. This was consistent with the fact that seasonal upwelling occurred in the area in summer ( $\mathrm{Zhu}$, 2003; Zhu et al., 2005), which might have a strong influence on the bottom-water physical and geochemical characteristics.

The sediment and pore-water geochemical parameters, especially $\mathrm{NH}_{4}-\mathrm{N}$ (ranging from $153.90 \mu \mathrm{M}$ to $1808.07 \mu \mathrm{M}$ ) and N/P (from 48.44 to 359.91) (Table 1), indicated significant eutrophication of most of our sampling stations. The highest values occurred at station S29 and the lowest at station S10.

\section{Diversity of the amoA libraries}

From the seven archaeal amoA libraries constructed, 637 clones were screened, and 47 RFLP genotypes and 29 OTUs were identified. Sampling station S7 had the highest diversity of the archaeal amoA genotypes, and stations S9 and S29 had the lowest diversity, based on the values of the Shannon-Wiener, reciprocal of Simpson and evenness indices calculated with both the RFLP genotypes and the OTUs data, except for station S9's evenness index calculated with the OTUs data (Table 2). The estimated coverages of the clone libraries were quite high (Table 2), together with the rarefaction analyses (Supplementary Fig. S1, available with the online version of this paper), indicating that these libraries might have captured the majority of the archaeal amoA sequence types in the studied environments with the primers used. However, analyses of the richness estimators $S_{\mathrm{ACE}}$ and $S_{\mathrm{Chao} 1}$ indicated that most of our sampling stations might have higher predicted archaeal amoA genotype diversity than recovered in the current study (Table 2 ).

\section{AmoA sequence phylogenies}

The 47 unique archaeal amoA gene sequences had 66.4$99.8 \%$ sequence similarity among each other, and had various degrees of identity $(87.8-99.7 \%)$ to the closest matched GenBank sequences. After translation, the corresponding protein sequences had 74.9-100.0\%

Fig. 2 Phylogenetic tree constructed with the distance and neighbour-joining methods of the archaeal AmoA sequences translated from the cloned amoA gene sequences recovered from the Changjiang Estuary and the adjacent East China Sea. Partial archaeal AmoA sequences of 185 aligned amino acid positions were used for tree construction. The tree branch distances represent amino acid substitution rate, and the scale bar represents the expected number of changes per homologous position. Bacterial AmoA sequences from Nitrosospira briensis and Nitrosomonas europaea were used as the outgroup. Bootstrap values greater than $70 \%$ of 100 resamplings are shown near nodes. Abbreviations: BS, Black Sea seawater; DRES, Douro River estuary, intertidal sandy flat (Portugal); ES_HL, Elkhorn Slough, Hudson's Landing, sediment (USA); HB, Huntington Beach, surf zone sediment (USA); MX, Bahia del Tobari, Gulf of California, estuarine sediments (Mexico); SBC, coast of Santa Barbara, marine sponge Axinella mexicana (USA); SF_CB, San Francisco Bay, Central Bay station 20, sediment (USA); SSFB, South San Francisco Bay, sediment (USA). 


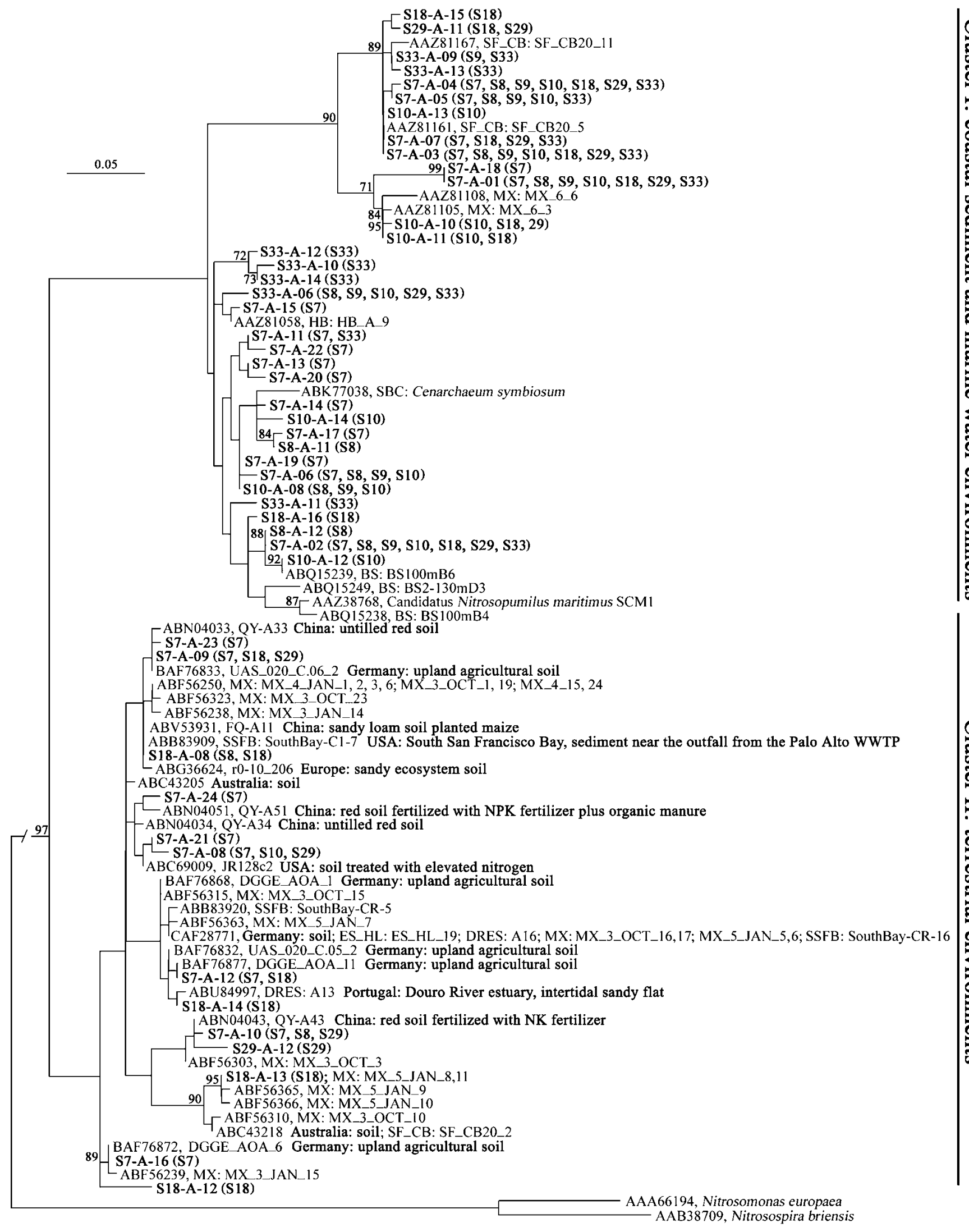

ABN04033, QY-A33 China: untilled red soil

BAF76833, UAS 020 C 062 Germany: upland agricultural soil

ABF56250, MX: MX_4_JAN_1, 2, 3, 6; MX_3_OCT_1, 19; MX_4_15, 24

ABV 53931 , FQ-AII China: sandy loam soil planted maize

ABB83909, SSFB: SouthBay-C1-7 USA: South San Francisco Bay, sediment near the outfall from the Palo Alto WWTP

ABG36624, r0-10_206 Europe: sandy ecosystem soil

$\mathrm{ABC} 43205$ Australia: soil

ABN04051, QY-A51 China: red soil fertilized with NPK fertilizer plus organic manure

Cha: untilled red soil

S7-A-21 (S7)

ABP83920 SSFB: SouthBay-CR-5

ABF56363 MX:MX 5 JAN 7

CAF28771, Germany: soil; ES_HL: ES_HL_19; DRES: A16; MX: MX_3_OCT_16,17; MX_5_JAN_5,6; SSFB: SouthBay-CR-16

S18-A-14 (S18)

ABN04043, QY-A43 China: red soil fertilized with NK fertilizer

ABF56303, MX: MX 3 OCT

-ABF56365, MX: MX_5_JAN_9

ABF56310, MX: MX_3_OCT_10

ABC43218 Australia: soil: SF_CB: SF_CB20_2

(

S7-A-16 (S7)

ABF56239, MX: MX 3 JAN 15

S18-A-12 (S18) 
sequence similarity among each other, and had quite high identities (95.2-100.0\%) to the closest matched GenBank sequences retrieved from a variety of terrestrial, estuarine, coastal and marine environments. Sequences that were related to soil or coastal sediment environments composed the majority $(59.6 \%)$ of our archaeal AmoA phylotypes, while the remaining sequences were related to marine water environments or the marine sponge Axinella mexicana.

The constructed phylogenetic tree showed that two AmoA sequence clusters could be identified based on $20 \%$ sequence distance cutoff determined via the DOTUR program (Fig. 2). Sequences associated with coastal sediment (San Francisco Bay, Gulf of California and Huntington Beach) or marine water (Black Sea) environments composed cluster I (Francis et al., 2005; Lam et al., 2007), and sequences having their closest matches mainly from terrestrial environments (Chinese, American, Australian and German soils) composed cluster II (Treusch et al., 2005; Leininger et al., 2006; He et al., 2007), although some estuarine sediment sequences were also affiliated within this cluster (Francis et al., 2005; Beman \& Francis, 2006; Park et al., 2006). The putative soil-related sequences of cluster II in our clone libraries mainly occurred at stations S7, S8, S18, S29, and occasionally at station S10. Their relative abundance accounted for $33.3 \%, 16.7 \%, 37.5 \%, 33.3 \%$ and $7.1 \%$ of the RFLP genotypes and $17.2 \%, 9.8 \%, 13.3 \%, 4.3 \%$ and $1.1 \%$ of the clones in each of the corresponding libraries. The change of their relative abundances in the various libraries indicated that the AOA of these sequences might mainly occur in the area close to the Changjiang River mouth.

Eleven sequences (59 clones) were closely (95.2-96.7\% identity) related to the ammonia-oxidizing Cenarchaeum symbiosum AmoA sequence (Hallam et al., 2006a). These sequences mainly occurred in sampling stations S7, S8, S9, S10 and S33. Five sequences (109 clones) were closely (94.3-96.2\% identity) related to the AmoA sequence of 'Candidatus Nitrosopumilus maritimus' SCM1 (Konneke et al., 2005), and they had wide distribution in the Changjiang Estuary and the adjacent East China Sea (Fig. 2).

Nearly $60 \%$ of the AmoA sequences occurred in only one of the sampling stations. Four sequences, S7-A-01, S7-A02, S7-A-03 and S7-A-04, which were related to Gulf of California and San Francisco Bay sediment and Black Sea water AmoA sequences, occurred in all the stations (Fig. 2). Some other sequences, such as S7-A-05, S33-A-06, S7-A-06 and S7-A-07, which were related to Cenarchaeum symbiosum or sedimentary archaeal AmoA sequences from San Francisco Bay and Huntington Beach, occurred in five or four of the sampling stations. These common sequences were also the most abundant ones ( $80.8 \%$ of the 637 clones screened) in the libraries.

\section{AOA community distribution in response to estuarine gradients}

UniFrac environmental clustering of the archaeal amoA clone libraries showed clear grouping of the AOA communities in the Changjiang Estuary and the adjacent East China Sea (data not shown). The amoA genotype assemblages of stations S8, S9 and S10 on the transect perpendicular to the East China Sea coastline (the 'perpendicular transect' hereafter) were grouped together, those of stations S18, S29 and S33 on the transect aslant to the coastline (the 'slant transect' hereafter) were grouped together, and the amoA genotype assemblage of station S7, which was at the intersection of the two transects, formed the third group. PCoA showed similar clustering of the archaeal amoA genotype assemblages, and the first two principal coordinates (P1 and P2) explained $78.29 \%$ of the total community variability (Fig. 3). Environmental clustering (data not shown) and PCoA (Supplementary Fig. S2) based on the archaeal AmoA protein sequences showed similar clustering of the sampling stations.

Spatial distribution of the sedimentary AOA communities in the Changiiang Estuary and the adjacent East China Sea may be influenced by river runoff and other related physico-chemical factors. CCA of the archaeal amoA genotype assemblages in response to seawater environmental variables confirmed this (Fig. 4a). The first two CCA axes explained $65.2 \%$ of the total variance in the amoA genotypes composition and $71.6 \%$ of the cumulative variance of the genotype-environment relationship. However, only surface-water salinity contributed significantly $(P=0.015, F=1.92,1000$ Monte Carlo permutations) to the amoA genotype-environment relationship, and this factor alone provided $27.8 \%$ of the total CCA explanatory power. The putative soil-related archaeal amoA OTUs had very restricted distribution in the CCA graph,

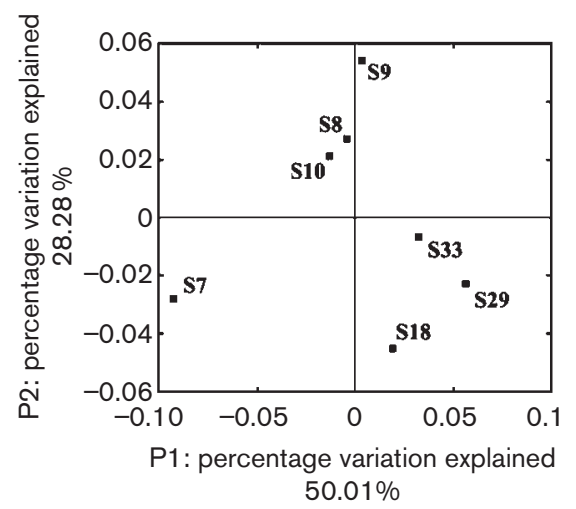

Fig. 3. $\mathrm{PCoA}$ of the sedimentary $\mathrm{AOA}$ communities with weighted UniFrac using the archaeal amo $A$ sequences recovered from the Changjiang Estuary and adjacent East China Sea. Shown is the plot of the first two principal coordinate axes for PCoA and the distribution of the AOA communities (designated with the sampling station names) in response to these axes. 

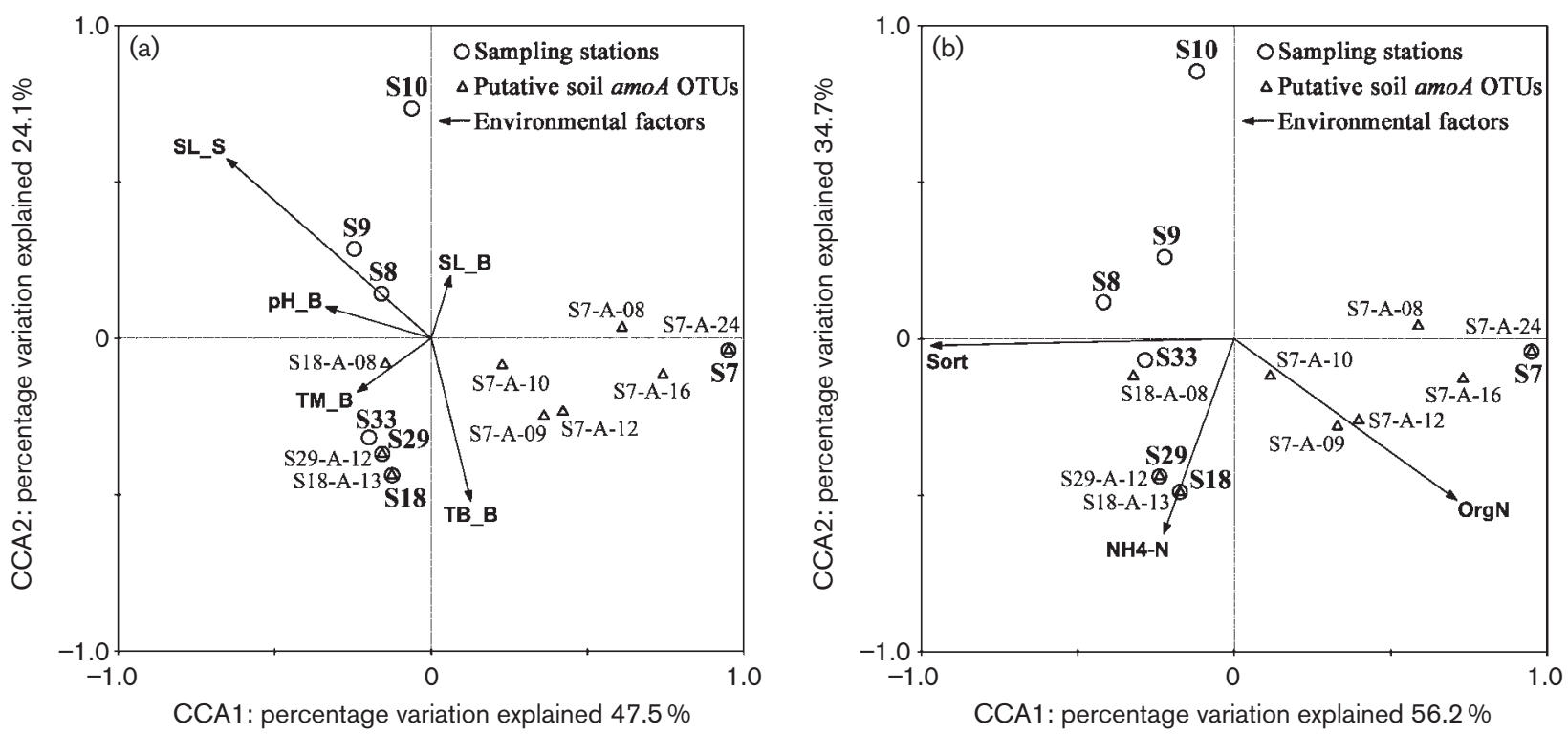

Fig. 4. CCA ordination plots for the first two dimensions of CCA of the relationship between the sedimentary AOA community compositions with (a) the hydrochemical parameters of the surface-water ( $S$ ) and bottom-water (B) environments and (b) the sedimentological and pore-water geochemical parameters in the Changjiang Estuary and adjacent East China Sea. The optimal CCA models represented by the diagrams were produced with manual deselection of collinear variables and automatic forward selection via Monte Carlo permutation significance tests, and with scaling of scores focused on inter-species distances. The eigenvalues of the first two axes (CCA1 and CCA2) were 0.382 and 0.194 , respectively, for (a), and 0.366 and 0.226 , respectively, for (b). The species-environment correlations of the first two axes (CCA1 and CCA2) were 0.994 and 1.000 , respectively, for (a), and 0.985 and 1.000 , respectively, for (b). Correlations between environmental variables and CCA axes are represented by the length and angle of arrows (environmental factor vectors). The distributions of the putative soil-AOA related OTUs in the CCA plots are shown; the other OTUs are not shown to avoid image cluttering. The raw 'CCA' analyses with all the measured environmental factors before model optimizations are shown in Supplementary Figs S3 and S4. Abbreviations: SL, salinity; Sort, sediment sorting coefficient; TB, turbidity; TM, temperature.

being mainly located on the negative half of the surfacewater salinity vector (Fig. 4a). The distribution of these OTUs in response to low surface-water salinity indicated that the potential source of these putative soil-related AOA might be freshwater input from the Changjiang River. Although none of the other factors made a statistically significant contribution to the amoA genotype-environment relationship $(P>0.200,1000$ Monte Carlo permutations), the combination of these environmental factors provided additionally $62.3 \%$ of the total CCA explanatory power. Moreover, the bottom-water turbidity seemed to have a positive correlation with the distribution of the putative soil-related amoA OTUs.

\section{AOA community distribution in response to sedimentological and geochemical gradients}

The first two axes of the CCA of the sedimentary AOA communities versus geochemical and sedimentological factors explained $77.1 \%$ of the total variance in the amoA genotypes composition and $90.9 \%$ of the cumulative variance of the genotype-environment relationship (Fig. 4b). However, only the sediment sorting coefficient, a measure of the distribution or variability of particle sizes in the sediment, contributed significantly $(P=0.045$, $F=2.49,1000$ Monte Carlo permutations) to the amoA genotype-environment relationship. This sedimentological factor alone provided $45.6 \%$ of the total CCA explanatory power. Neither $\mathrm{NH}_{4}-\mathrm{N}$ nor OrgN made a statistically significant contribution to the microbe-environment relationship ( $P>0.25,1000$ Monte Carlo permutations), although distinct spatial distribution of the AOA assemblages along their gradients could be identified (Fig. $4 \mathrm{~b}$ ). Moreover, the geochemical variable OrgN seemed to have a positive correlation with the distribution of the putative soil-related amoA OTUs (Fig. 4b).

\section{DISCUSSION}

Most of our putative archaeal amoA (especially AmoA) sequences had quite high similarity with known sequences from various soil environments or coastal and estuarine environments of the East Pacific Ocean (Fig. 2) (Francis et al., 2005; Treusch et al., 2005; Beman \& Francis, 2006; Hallam et al., 2006a; Leininger et al., 2006; Park et al., 2006; He et al., 2007; Lam et al., 2007). Comparison with the sediment archaeal amoA communities of the hypernutri- 
fied subtropical Bahía del Tóbari Estuary (Beman \& Francis, 2006) indicated that the Changjiang Estuary and the adjacent East China Sea harboured similar AOA diversity. The high sequence similarity between the two estuaries indicates that similar archaeal AOA communities might exist in similar estuarine environments across the Pacific Ocean, despite the great geographical distance.

The Changjiang Estuary is an important interface of the terrestrial and marine environments; it is also highly complex and dynamic. The CDW has been found to split into two branches upon entering the East China Sea near the Changjiang River mouth in summer. One flowed southeastwards, and the other northeast-northwards (Chen et al., 2003; Zhu et al., 2005). The slow change of surface-water salinity along the slant transect indicated that part of the CDW flowed south-eastwards along the coastline during our sampling period. The sharp increase of surface-water salinity along the perpendicular transect indicated that the Changjiang freshwater runoff in the eastward direction was blocked by the offshore marine water or the northward intrusion of the TWC. Due to these differences, there were differences in the water physico-chemical properties between the two sampling transects. Surface water on the slant transect was more turbid than that on the perpendicular transect (not including station S7). This distinction could also be found in the difference of the sedimentary AOA assemblages (Figs 3 and 4; Supplementary Fig. S2).

The archaeal diversity in estuaries might be greater than that in the adjacent open oceans due to allochthonous terrestrial inputs, of which river water runoff might form the major source of particle-attached archaea in estuarine waters (Crump \& Baross, 2000; Wells \& Deming, 2003; Wells et al., 2006). Some studies have indicated that the AOA communities in terrestrial environments are distinct from those in marine environments (Leininger et al., 2006), while other studies have indicated that estuaries might harbour mixed populations of both soil and sediment AOA (Francis et al., 2005; Beman \& Francis, 2006). The deposition of microbes from the water column with freshwater input could potentially explain the existence of the putative soilrelated archaeal AmoA sequences in the estuarine sedimentary environments. In the Changjiang estuarine area, besides freshwater, nutrients, organic matter and suspended particles, the CDW might also contribute to the transport of terrestrial micro-organisms into the seawater and sediments along its flow path. The distribution of terrestrial AOA in estuarine environments might be a common phenomenon based on AmoA phylogenetic analyses (Fig. 2) (Francis et al., 2005; Beman \& Francis, 2006), illustrating the potentially important effect of river freshwater on the coastal sedimentary AOA composition. Our results also indicate that the putative soil-related AOA in estuarine sedimentary environments might serve as a bioindicator or biotracer of riverine impact on the coastal benthic microbial ecosystem.

Station S7 had the highest diversity of archaeal amoA genotypes among all the sampling stations. This station received the strongest impact of freshwater discharge from the Changjiang River. It was also located in the estuarine mixing zone, and the consequential maximum-turbidity zone of the East China Sea. Particles could be a source of riverine archaea in estuaries (Crump \& Baross, 2000; Wells \& Deming, 2003; Wells et al., 2006). Particles might also be a source of small organic compounds and potentially serve as a nutrient source for marine archaea, as studies have indicated that some marine crenarchaeota could utilize amino acids heterotrophically (Ouverney \& Fuhrman, 2000; Teira et al., 2006). The positive correlation of the S7 station amoA genotype assemblage with the sediment OrgN (Fig. 4b), although not statistically significant $(P>0.25,1000$ Monte Carlo permutations), provides certain clues to the above reasoning. Furthermore, the distribution of the sedimentary archaeal amoA genotype assemblages also strongly correlated with surface-water turbidity (Supplementary Fig. S3). However, because of the collinearity between surface-water salinity and turbidity $(r=-0.814)$, the exact contributions of these environmental factors could hardly be distinguished from each other. The edge effect of strong riverine-marine water interactions at the sharp estuarine salinity front around the S7 sampling station might provide a unique ecotone for the development and maintenance of a species-rich AOA assemblage (Chen et al., 2003; Ries et al., 2004; Zhu et al., 2005).

Some $30.0 \%$ of our sedimentary AmoA sequences had their closest match to sequences originally retrieved from marine water environments (Lam et al., 2007). This indicates that sediment and seawater might share some common or similar AOA micro-organisms (Beman \& Francis, 2006), or that exchange of AOA between sediment and seawater environments might occur in the Changiiang Estuary and East China Sea, via particle deposition, sediment resuspension or other mechanisms. A recent study indicated that the deep-sea sediments might harbour AOA communities distinct from those of the water columns of the deep oceans (Nakagawa et al., 2007). Significant differences might exist between coastal and deep-sea environments in the effect of the water-sediment interactions on the sedimentary AOA communities. High rates of particle deposition and sediment resuspension in coastal waters, especially near large river estuaries, might provide stronger exchange between the water and sediment AOA communities.

Multivariate statistical analyses indicated that the spatial distribution of the sedimentary amoA genotype assemblages correlated significantly with the surface-water salinity and sediment sorting coefficient (Fig. 4a, b), indicating potential influences of Changiiang River freshwater runoff and sedimentological condition on the sedimentary AOA community. The influence of the sedimentological condition on the sedimentary AOA community could be complicated. Sedimentological conditions were mainly related to the in situ hydrological regime, such as currents, tides, waves, upwelling, lateral 
transport, water mixing and exchange, and the intensity and dynamics of these activities. The correlation of the sediment sorting coefficient with archaeal amoA genotype assemblages could be related directly or indirectly to hydrological activities, via their impact on the sediment source, composition, organic matter content, pore-water redox, nutrient composition and concentration, and other physico-chemical, sedimentological or geochemical factors. Although we do not know the exact mechanism at present, our work is probably the first to show a direct correlation of a sedimentological factor with the distribution and structure of the sedimentary AOA community in an estuarine and continental shelf environment. However, because of the covariability of some of the environmental factors (Supplementary Figs S3 and S4), the exact influence and contribution of each environmental factor cannot be determined with certainty at present.

In summary, the diversity and spatial distribution of the sedimentary AOA have been studied in the Changjiang Estuary and adjacent East China Sea for the first time via analyses of the functional marker gene amoA. Our work indicated that this estuarine area might harbour similar sediment AOA communities to those of the East Pacific Ocean, and the transport of terrestrial AOA via river freshwater runoff might contribute to the composition and diversity of the estuarine sedimentary AOA communities.

\section{ACKNOWLEDGEMENTS}

The authors would like to thank Drs Christopher Francis and Michael Beman from Stanford University for their kind provision of information on the archaeal $a m o A$ primers. The authors would also like to express their appreciation to the three anonymous reviewers and the journal editor, Dr Werner Liesack. With their critiques and suggestions, the manuscript was improved greatly in scientific accuracy. This work was financially supported by the China National Natural Science Foundation grants 40576069 and 40576061, the Hi-Tech Research and Development Program of China grant 2007AA091903, the China Ocean Mineral Resources R\&D Association grants DYXM-115-02-2-6 and DYXM-115-02-2-20, and the China National Key Basic Research Program from the Ministry of Science and Technology grant 2002CB412400.

\section{REFERENCES}

Altschul, S. F., Madden, T. L., Schaffer, A. A., Zhang, J., Zhang, Z., Miller, W. \& Lipman, D. J. (1997). Gapped BLAST and PSI-BLAST: a new generation of protein database search programs. Nucleic Acids Res 25, 3389-3402.

Beman, J. M. \& Francis, C. A. (2006). Diversity of ammonia-oxidizing archaea and bacteria in the sediments of a hypernutrified subtropical estuary: Bahia del Tobari, Mexico. Appl Environ Microbiol 72, 7767-7777.

Beman, J. M., Roberts, K. J., Wegley, L., Rohwer, F. \& Francis, C. A. (2007). Distribution and diversity of archaeal ammonia monooxygenase $(a m o A)$ genes associated with corals. Appl Environ Microbiol 73, 5642-5647.

Brown, M. V. \& Bowman, J. P. (2001). A molecular phylogenetic survey of sea-ice microbial communities (SIMCO). FEMS Microbiol Ecol 35, 267-275.
Caffrey, J. M., Bano, N., Kalanetra, K. \& Hollibaugh, J. T. (2007). Ammonia oxidation and ammonia-oxidizing bacteria and archaea from estuaries with differing histories of hypoxia. ISME J 1, 660-662.

Cavicchioli, R., Demaere, M. Z. \& Thomas, T. (2007). Metagenomic studies reveal the critical and wide-ranging ecological importance of uncultivated archaea: the role of ammonia oxidizers. Bioessays 29, 1114.

Chai, C., Yu, Z. M., Song, X. X. \& Cao, X. H. (2006). The status and characteristics of eutrophication in the Yangtze River (Changjiang) Estuary and the adjacent East China Sea, China. Hydrobiologia 563, 313-328.

Chen, C., Zhu, J., Beardsley, R. C. \& Franks, P. J. S. (2003). Physicalbiological sources for dense algal blooms near the Changjiang River. Geophys Res Lett 30, 22.1-22.4.

Coolen, M. J. L., Abbas, B., van Bleijswijk, J., Hopmans, E. C., Kuypers, M. M. M., Wakeham, S. G. \& Sinninghe Damsté, J. S. (2007). Putative ammonia-oxidizing Crenarchaeota in suboxic waters of the Black Sea: a basin-wide ecological study using 16S ribosomal and functional genes and membrane lipids. Environ Microbiol 9, 1001-1016.

Crump, B. C. \& Baross, J. A. (2000). Archaeaplankton in the Columbia River, its estuary and the adjacent coastal ocean, USA. FEMS Microbiol Ecol 31, 231-239.

Dang, H. Y. \& Lovell, C. R. (2000). Bacterial primary colonization and early succession on surfaces in marine waters as determined by amplified rRNA gene restriction analysis and sequence analysis of $16 \mathrm{~S}$ rRNA genes. Appl Environ Microbiol 66, 467-475.

DeLong, E. F. (1992). Archaea in coastal marine environments. Proc Natl Acad Sci U S A 89, 5685-5689.

Falkowski, P. G. (1997). Evolution of the nitrogen cycle and its influence on the biological sequestration of $\mathrm{CO}_{2}$ in the ocean. Nature 387, 272-275.

Felsenstein, J. (1989). PHYLIP - phylogeny inference package (version 3.2). Cladistics 5, 164-166.

Francis, C. A., Roberts, K. J., Beman, J. M., Santoro, A. E. \& Oakley, B. B. (2005). Ubiquity and diversity of ammonia-oxidizing archaea in water columns and sediments of the ocean. Proc Natl Acad Sci U S A 102, 14683-14688.

Francis, C. A., Beman, J. M. \& Kuypers, M. M. M. (2007). New processes and players in the nitrogen cycle: the microbial ecology of anaerobic and archaeal ammonia oxidation. ISME J 1, 19-27.

Hall, T. A. (1999). BioEdit: a user-friendly biological sequence alignment editor and analysis program for Windows 95/98/NT. Nucleic Acids Symp Ser 41, 95-98.

Hallam, S. J., Konstantinidis, K. T., Putnam, N., Schleper, C., Watanabe, Y., Sugahara, J., Preston, C., de la Torre, J., Richardson, P. M. \& Delong, E. F. (2006a). Genomic analysis of the uncultivated marine crenarchaeote Cenarchaeum symbiosum. Proc Natl Acad Sci U S A 103, 18296-18301.

Hallam, S. J., Mincer, T. J., Schleper, C., Preston, C. M., Roberts, K., Richardson, P. M. \& DeLong, E. F. (2006b). Pathways of carbon assimilation and ammonia oxidation suggested by environmental genomic analyses of marine Crenarchaeota. PLoS Biol 4, e95.

He, J. Z., Shen, J. P., Zhang, L. M., Zhu, Y. G., Zheng, Y. M., Xu, M. G. \& $\mathrm{Di}, \mathrm{H}$. (2007). Quantitative analyses of the abundance and composition of ammonia-oxidizing bacteria and ammonia-oxidizing archaea of a Chinese upland red soil under long-term fertilization practices. Environ Microbiol 9, 2364-2374.

Herndl, G. J., Reinthaler, T., Teira, E., van Aken, H., Veth, C., Pernthaler, A. \& Pernthaler, J. (2005). Contribution of Archaea to total prokaryotic production in the deep Atlantic Ocean. Appl Environ Microbiol 71, 2303-2309. 
Ichikawa, H. \& Beardsley, R. C. (2002). The current system in the Yellow and East China seas. J Oceanogr 58, 77-92.

Ingalls, A. E., Shah, S. R., Hansman, R. L., Aluwihare, L. I., Santos, G. M., Druffel, E. R. \& Pearson, A. (2006). Quantifying archaeal community autotrophy in the mesopelagic ocean using natural radiocarbon. Proc Natl Acad Sci U S A 103, 6442-6447.

Jiao, N., Zhang, Y., Zeng, Y., Gardner, W. D., Mishonov, A. V., Richardson, M. J., Hong, N., Pan, D., Yan, X. H. \& other authors (2007). Ecological anomalies in the East China Sea: impacts of the Three Gorges Dam? Water Res 41, 1287-1293.

Jonasson, A. \& Olausson, E. (1966). New devices for sediment sampling. Mar Geol 4, 365-372.

Konneke, M., Bernhard, A. E., de la Torre, J. R., Walker, C. B., Waterbury, J. B. \& Stahl, D. A. (2005). Isolation of an autotrophic ammonia-oxidizing marine archaeon. Nature 437, 543-546.

Lam, P., Jensen, M. M., Lavik, G., McGinnis, D. F., Muller, B., Schubert, C. J., Amann, R., Thamdrup, B. \& Kuypers, M. M. (2007). Linking crenarchaeal and bacterial nitrification to anammox in the Black Sea. Proc Natl Acad Sci U S A 104, 7104-7109.

Leininger, S., Urich, T., Schloter, M., Schwark, L., Qi, J., Nicol, G. W., Prosser, J. I., Schuster, S. C. \& Schleper, C. (2006). Archaea predominate among ammonia-oxidizing prokaryotes in soils. Nature 442, 806-809.

Lepš, J. \& Šmilauer, P. (2003). Multivariate Analysis of Ecological Data Using CANOCO. Cambridge, UK: Cambridge University Press.

Li, D. \& Daler, D. (2004). Ocean pollution from land-based sources: East China Sea, China. Ambio 33, 107-113.

Li, D. J., Zhang, J., Huang, D. J., Wu, Y. \& Liang, J. (2002). Oxygen depletion off the Changjiang (Yangtze River) Estuary. Sci China (Series D) 45, 1137-1146.

Lozupone, C. \& Knight, R. (2005). UniFrac: a new phylogenetic method for comparing microbial communities. Appl Environ Microbiol 71, 8228-8235.

Lozupone, C. A., Hamady, M., Kelley, S. T. \& Knight, R. (2007). Quantitative and qualitative $\beta$ diversity measures lead to different insights into factors that structure microbial communities. Appl Environ Microbiol 73, 1576-1585.

Magalhães, C., Bano, N., Wiebe, W. J., Bordalo, A. A. \& Hollibaugh, J. T. (2007). Dynamics of nitrous oxide reductase genes (nos $Z$ ) in intertidal rocky biofilms and sediments of the Douro River Estuary (Portugal), and their relation to N-biogeochemistry. Microb Ecol 55, 259-269.

Mincer, T. J., Church, M. J., Taylor, L. T., Preston, C., Karl, D. M. \& DeLong, E. F. (2007). Quantitative distribution of presumptive archaeal and bacterial nitrifiers in Monterey Bay and the North Pacific Subtropical Gyre. Environ Microbiol 9, 1162-1175.

Mullins, T. D., Britschgi, T. B., Krest, R. L. \& Giovannoni, S. J. (1995). Genetic comparisons reveal the same unknown bacterial lineages in Atlantic and Pacific bacterioplankton communities. Limnol Oceanogr 40, 148-158.

Nakagawa, T., Mori, K., Kato, C., Takahashi, R. \& Tokuyama, T. (2007). Distribution of cold-adapted ammonia-oxidizing microorganisms in the deep-ocean of the northeastern Japan Sea. Microbes Environ 22, 365-372.

Nicol, G. W. \& Schleper, C. (2006). Ammonia-oxidising Crenarchaeota: important players in the nitrogen cycle? Trends Microbiol 14, 207-212.

Ouverney, C. C. \& Fuhrman, J. A. (2000). Marine planktonic archaea take up amino acids. Appl Environ Microbiol 66, 4829-4833.

Park, H. D., Wells, G. F., Bae, H., Criddle, C. S. \& Francis, C. A. (2006). Occurrence of ammonia-oxidizing archaea in wastewater treatment plant bioreactors. Appl Environ Microbiol 72, 5643-5647.
Ries, L., Fletcher, R. J., Jr, Battin, J. \& Sisk, T. D. (2004). Ecological responses to habitat edges: mechanisms, models, and variability explained. Annu Rev Ecol Evol Syst 35, 491-522.

Sambrook, J. \& Russell, D. W. (2001). Molecular Cloning: a Laboratory Manual, 3rd edn. Cold Spring Harbor, NY: Cold Spring Harbor Laboratory.

Schloss, P. D. \& Handelsman, J. (2005). Introducing DOTUR, a computer program for defining operational taxonomic units and estimating species richness. Appl Environ Microbiol 71, 1501-1506.

Seitzinger, S. P. (1988). Denitrification in freshwater and coastal marine ecosystems: ecological and geochemical significance. Limnol Oceanogr 33, 702-724.

Sekiguchi, H., Koshikawa, H., Hiroki, M., Murakami, S., Xu, K., Watanabe, M., Nakahara, T., Zhu, M. \& Uchiyama, H. (2002). Bacterial distribution and phylogenetic diversity in the Changjiang Estuary before the construction of the Three Gorges Dam. Microb Ecol 43, 82-91.

Teira, E., van Aken, H., Veth, C. \& Herndl, G. J. (2006). Archaeal uptake of enantiomeric amino acids in the meso- and bathypelagic waters of the North Atlantic. Limnol Oceanogr 51, 60-69.

ter Braak, C. J. F. \& Šmilauer, P. (2002). CANOCO Reference Manual and CanoDraw for Windows User's Guide: Software for Canonical Community Ordination (version 4.5). Ithaca, NY: Microcomputer Power.

Thompson, J. D., Higgins, D. G. \& Gibson, T. J. (1994). CLUSTAL W: improving the sensitivity of progressive multiple sequence alignment through sequence weighting, position-specific gap penalties and weight matrix choice. Nucleic Acids Res 22, 4673-4680.

Treusch, A. H., Leininger, S., Kletzin, A., Schuster, S. C., Klenk, H. P. \& Schleper, C. (2005). Novel genes for nitrite reductase and Amorelated proteins indicate a role of uncultivated mesophilic crenarchaeota in nitrogen cycling. Environ Microbiol 7, 1985-1995.

Venter, J. C., Remington, K., Heidelberg, J. F., Halpern, A. L., Rusch, D., Eisen, J. A., Wu, D., Paulsen, I., Nelson, K. E. \& other authors (2004). Environmental genome shotgun sequencing of the Sargasso Sea. Science 304, 66-74.

Vetriani, C., Jannasch, H. W., MacGregor, B. J., Stahl, D. A. \& Reysenbach, A. L. (1999). Population structure and phylogenetic characterization of marine benthic archaea in deep-sea sediments. Appl Environ Microbiol 65, 4375-4384.

Wells, L. E. \& Deming, J. W. (2003). Abundance of Bacteria, the Cytophaga-Flavobacterium cluster and Archaea in cold oligotrophic waters and nepheloid layers of the Northwest Passage, Canadian Archipelago. Aquat Microb Ecol 31, 19-31.

Wells, L. E., Cordray, M., Bowerman, S., Miller, L. A., Vincent, W. F. \& Deming, J. W. (2006). Archaea in particle-rich waters of the Beaufort Shelf and Franklin Bay, Canadian Arctic: clues to an allochthonous origin? Limnol Oceanogr 51, 47-59.

Wuchter, C., Schouten, S., Boschker, H. T. \& Sinninghe Damste, J. S. (2003). Bicarbonate uptake by marine Crenarchaeota. FEMS Microbiol Lett 219, 203-207.

Wuchter, C., Abbas, B., Coolen, M. J., Herfort, L., van Bleijswijk, J., Timmers, P., Strous, M., Teira, E., Herndl, G. J. \& other authors (2006). Archaeal nitrification in the ocean. Proc Natl Acad Sci U S A 103, 12317-12322.

Yanagi, T. (1994). Material transport in the Yellow/East China Seas. Bull Coast Oceanogr 31, 239-256.

Zeng, Y., Li, H. \& Jiao, N. (2007). Phylogenetic diversity of planktonic archaea in the estuarine region of East China Sea. Microbiol Res 162, 26-36.

Zhang, Y. \& Jiao, N. (2007). Dynamics of aerobic anoxygenic phototrophic bacteria in the East China Sea. FEMS Microbiol Ecol 61, 459-469. 
Zhang, J., Zhang, Z. F., Liu, S. M., Wu, Y., Xiong, H. \& Chen, T. (1999). Human impacts on the large world rivers: would the Changiiang (Yangtze River) be an illustration? Global Biogeochem Cycles 13, 1099-1105.

Zhu, J. R. (2003). Dynamic mechanism of the upwelling on the west side of the submerged river valley off the Changjiang mouth in summertime. Chin Sci Bull 48, 2754-2758.
Zhu, J. R., Wang, J. H., Shen, H. T. \& Wu, H. (2005). Observation and analysis of the diluted water and red tide in the sea off the Changiiang River mouth in middle and late June 2003. Chin Sci Bull 50, 240-247.

Edited by: W. Liesack 